Invitado Internacional

\title{
La mirada de los viajeros y científicos decimonónicos sobre la movediza gea chilensis
}

\section{The glance of travellers and scientists of the 19th century about the moving "gea chilensis"}

\author{
M Zenobio Saldivia ${ }^{1}$ \\ ${ }^{1}$ Universidad Tecnológica Metropolitana, Chile
}

\section{Resumen}

Se analiza la visión de la naturaleza chilena y el impacto de los movimientos telúricos en el cuerpo físico de Chile y en el imaginario colectivo nacional, que se forjaron tanto los científicos decimonónicos chilenos y extranjeros y algunos viajeros con estudios de historia natural, como María Graham. Y a partir de tales percepciones se reflexiona sobre la conveniencia de tener presente esta realidad en los ámbitos de las políticas públicas y la educación.

Palabras clave: Naturaleza chilena, Siglo XIX, terremotos, comunidad científica

\begin{abstract}
This paper analyses the vision of Chilean nature and the impact of earthquakes on the physical body of Chile and in the national collective imagination, that were forged Chilean and foreign nineteenth-century scientists and travelers with some natural history studies as Mary Graham. And from such perceptions reflect on whether to take in to account this reality in the fields of public policy and education.
\end{abstract}

Key words: Chilean nature, XIX century, earthquakes, scientific community

\section{Resumo}

Se analisa a visão chilena da natureza com base nos terremotos do Chile e do imaginário coletivo nacional, que forjaramos pensamentos tanto dos cientistas chilenos, estrangeiros e as populações do século passado com os estudos de história natural desenvolvidos pelas análises de Maria Graham. E a partir de tais reflexões se propõem ter esta realidade nos âmbitos das políticas públicas da educação.

Palavras-chave: Natureza chilena, século XIX, terremotos, cientistas

Correspondencia: M Zenobio Saldivia. Universidad Tecnológica Metropolitana. revistalogos@policia.edu.co 


\section{Introducción}

El cuerpo físico de Chile está conformado por valles interiores y por la presencia de la Cordillera de los Andes, al Oriente; matizada de volcanes y por su extensa costa del Pacífico, al Occidente. Y en la costa del Pacífico, como es sabido, se ubican la placa de Nazca que se desplaza desde la Isla de Pascua hasta las Galápagos y la placa Sudamericana, que hace lo propio entre las costas de Perú y Chile (Claro Tocornal, 2007, p. 9). Por ello, es frecuente que se generen eventualmente ciertas fricciones entre las placas, las que se traducen en el cuerpo físico de Chile y en el de Perú, ora en sismos menores, ora terremotos con o sin tsunamis. La historia de tales expresiones de la naturaleza específicamente chilena, ha quedado de manifiesto principalmente a partir de la conquista y del período colonial, puesto que los españoles nos han legado una escueta información sobre dichos sucesos. Empero, es a partir de la consolidación de Chile como República, cuando es posible encontrar más datos y una prosa significativa al respecto, articulada tanto por los científicos y viajeros que recorren el territorio en este periodo de tiempo, como también por los aportes de eventuales organismos y medios comunicacionales que principian a descollar en el país. En efecto, en cuanto a los sabios que nos han legado información, recordemos el trabajo de los naturalistas contratados por el gobierno como Claudio Gay, Rodulfo Amando Philippi o Ignacio Domeyko. Así como también, gracias a los datos aportados por el científico Charles Darwin, quien luego de su paso por Chile, nos dejó claras descripciones de dichos fenómenos naturales, tanto en relación con lo científico como con lo social costumbrista. Lo propio acontece con viajeros o viajeras como María Graham, entre tantos otros. Y en relación con organismos dedicados al acopio de los datos sobre terremotos y sobre todos los fenómenos de la naturaleza y la sociedad, que pueden ser considerados objetos de estudio, recordemos la creación en 1843, de la Oficina de Estadística (Urzúa Valenzuela, 1970, p. 88), o el medio comunicacional de la Universidad de Chile, instaurada también en 1843, que comienza a dar vida a su revista científica desde 1846, "Los Anales de la Universidad de Chile" (Anales de la Universidad de Chile, 1846).

Por ello, en lo que sigue, analizaremos la visión que nos han legado en su prosa dichos sabios y viajeros, para arribar a ciertas correlaciones entre los sabios mencionados, para luego apreciar el impacto de estas expresiones telúricas en el imaginario colectivo nacional y colegir de allí la conveniencia de internalizar en los jóvenes y estudiantes chilenos y latinoamericanos contemporáneos en general, una mentalidad de aceptación positiva de tales sucesos y cautelar reacciones masivas que contribuyan al orden público, a la estabilidad social y a un mayor respeto por el prójimo en tales situaciones límites.

\section{Los terremotos en el Chile decimonónico}

Entre los terremotos más fuertes ocurridos en Chile ya constituido como República, cabe destacar los siguientes: el de 1819, en Copiapó, (con tsunami); el de 1822 en Santiago y el mismo año en Valparaíso, (con tsunami moderado); el de 1832 en Huasco; el de 1835 en Concepción (con tsunami); el de 1837, en Valdivia y Chiloé; el de La Ligua en 1847; el de 1850, en el Valle del Maipo; el de 1851, en Casablanca y Copiapó; el de 1855 nuevamente en Concepción; el del 13 de agosto 1868, que afectó desde la zona norte hasta Valparaíso; o el de 1880 en Illapel y Petorca, entre tantos otros.(Barrio,1985. Claro Tocornal, p. 9, 10. Domeyko, 1857, p. 9 ss. El Araucano, 1937), y, por supuesto, los científicos y viajeros extranjeros que se encontraban en tales fechas en el país. Todos nos han dejado sus descripciones sobre dichos sucesos, algunas de las cuales se analizan a continuación:

\section{El terremoto de 1822 y la mirada de María Graham}

Este ocurre el 19 de noviembre y afecta a las regiones ubicadas desde Illapel hasta Chiloé. Y por esta fecha se encuentra en Chile recorriendo Valparaíso, la viajera María Graham, naturalista y escritora inglesa. Su descripción del fenómeno telúrico se percibe matizada por el asombro, la ansiedad y la captación de la belleza del paisaje. Así, por ejemplo, en su prosa menciona que los terremotos son algo frecuente en el país y que los sismos o posteriores réplicas no constituyen un óbice para continuar con los paseos a caballo por la zona de Valparaíso, Casablanca y Quintero, lugares donde observa especímenes arbóreos y florísticos que la cautivan por su policromía y sus olores. En todo caso, llama la atención que la viajera intente buscar un correlato entre los terremotos y el clima, para apreciar, finalmente, la delicadeza del clima. Graham señala:

(...)no concibo un clima mejor que el de Chile, ni 
más delicioso para los que en él habitan; i ahora que estoy acostumbrada a las convulsiones de la tierra, me parecen un mal menor de lo que antes podría haber imaginado(...). ( Graham, 1909, p. 205)

Aquí la viajera destaca a los temblores como algo característico de la geografía chilensis y valora la constancia del clima que es en general parejo, sin grandes contrastes. Por otro lado, la topografía del país también impresiona a la viajera; así por ejemplo, luego de su recorrido por el camino de Valparaíso a Santiago, describe los sectores de Curacaví, Cuesta de Zapata, o Pudahuel entre otros, y en relación con los cerros que se perciben desde la Cuesta de Zapata, expresa:

(...)los elevados cerros que rodean la ciudad i la cadena de montañas más espléndidas del mundo, la cordillera de los Andes, coronada por la nieve, con sus cimas que parecen llegar al cielo i sus oscuras quebradas en que flotan densas masas de nubes, ofrecían a mi vista una escena que jamás había contemplado antes. (Graham, 1909, p. 8)

Luego, al visitar el sector de Concón, señala:

Los cerros de Concón, presentan un carácter mui diverso de los que rodean a Valparaíso. Allá una arcilla rojiza, con venas de granito i de cuarzo blanco, forma todo o casi toda la masa de los cerros; los de esta rejion son de una arena gris o negrusca; con capas de piedrecillas i conchas visibles a diferentes alturas frente a la playa. (Graham, 1909, p. 164)

María Graham, por tanto, nos entrega una mirada del cuerpo físico de Chile, que no se agota en los aspectos puramente inorgánicos, topográficos u orográficos, sino que va dando cuenta del cuerpo físico del país, en los ámbitos orgánicos e inorgánicos, con una prosa esencialmente descriptiva, centrada en la policromía, en los olores, en las formas de la naturaleza y en la interfaz de los lugareños con la tierra y sus productos y con sus costumbres; esto es, un enfoque romántico que nos recuerda claramente la prosa de Humboldt. Y lo más significativo del discurso de la autora inglesa, es que nos ha legado una percepción del cuerpo físico de un país en el cual coexisten el dinamismo de los fenómenos telúricos imbricados y aceptados en la propia idiosincrasia de sus habitantes, quienes entienden que la vida es una concatenación universal entre lo físico, lo biológico y lo social y que por ello hay que continuar con los proyectos personales y/o con el proyecto de consolidación de la República.

\section{El terremoto de 1835 y la percepción de Darwin}

El 20 de enero de 1835, Concepción y otras ciudades cercanas sufrieron un fuerte terremoto que según estimaciones contemporáneas habría sido de 8, 2 grados. A la sazón, Charles Darwin se encontraba en el puerto de San Carlos de Chiloé, realizando sus observaciones habituales de especímenes de la región. El sabio inglés, queda muy impresionado por el fenómeno y lo expresa con estas palabras:

(...)durante la noche del 19 de Enero el volcán Osorno se pone en erupción. A medianoche, el centinela observa algo que se parece a una gran estrella, ésta aumenta a cada instante, y a las tres de la madrugada asistimos al más magnífico de los espectáculos. Con ayuda del telescopio, vemos en medio de espléndidas llamas rojas, negros objetos proyectados incesantemente al aire, que después caen". - Y enseguida añade-“ (...) He quedado muy sorprendido al saber más tarde que el Aconcagua, en Chile, 480 millas (772 kilómetros) más al Norte, se puso en erupción durante la misma noche; y me asombró más aún al llegar a mi noticias de que la gran erupción del Cosiguina (2700 millas, 4343 kilómetros al Norte del Aconcagua), acompañada de un terremoto que se hizo sentir en un radio de 1.000 millas, había tenido lugar seis horas después. (Darwin, 1945, p. 349)

Semanas más tarde, desembarca en Talcahuano y sigue a caballo hacia Concepción, y nuevamente hace constar su asombro en estos términos:

Las dos ciudades presentan el más terrible espectáculo, pero al mismo tiempo el más interesante que jamás me haya sido dado contemplar... El terremoto comenzó a las once y media de la mañana. Si hubiera ocurrido a media noche, el mayor número de habitantes, que en esta sóla provincia, ascienden a muchos millares, habrían perecido. En suma no hubo sino un centenar de víctimas(... ). (Darwin, 1945, p. 362-363)

Aquí, en Concepción, se percata de la destrucción de edificios y de la muerte de al menos 500 personas, y del dolor de millares de sobrevivientes; todo lo cual lo impacta y lo 
motiva a seguir con más ahínco con sus investigaciones sociológicas, costumbristas y taxonómicas.

En rigor, Darwin ve a Chile como un territorio dinámico, rico en cuanto a la diversidad de especímenes bióticos, por su abundancia de aves, mamíferos, peces, pequeños roedores y otros, así como por la policromía bullente de su flora nativa, especialmente en las zonas de Valdivia, Chiloé y la Patagonia Occidental. Pero además percibe el cuerpo físico de Chile como rico en minerales y recursos hídricos, especialmente en la zona del Norte, matizada de minas de plata y cobre. Empero, el científico deja también muy claro que los nativos y lugareños entienden a su naturaleza, a su entorno y que la han asumido con todas sus bondades y dificultades. Para lo primero recuérdese que muchos científicos y viajeros ya han mencionado que en Chile el clima es benigno y no hay temperaturas muy extremas entre una estación y otra. Y para lo segundo, recuérdese también que tanto los viajeros, como los científicos han dejado de manifiesto que el cuerpo físico del país posee una riqueza enorme en términos de minerales para explotar, principalmente cobre, plata y carbón, entre otros.

Ahora, lo esencial en las miradas de Darwin y de Graham, es el sentimiento de aceptación de los chilenos de su realidad telúrica y la convicción de sus habitantes de seguir interactuando con su naturaleza y sus especímenes para la obtención del progreso.

Este terremoto también fue descrito y divulgado en su tiempo, en algunas revistas y/o Academias y Sociedades Científicas europeas. En efecto, en uno de los números del año 1837 del órgano comunicacional oficial del gobierno chileno, el diario El Araucano, se aprecia una nota traducida por Andrés Bello intitulada: "Noticia del gran terremoto acaecido en Chile el 20 de febrero de 1835, por Alejandro Caldcleugh", donde el científico informante destaca que en los momentos antes de dicho evento, hubo "una ajitacion extraordinaria de las ratas en los techos de las casas" y se observó el desplazamiento de "inmensas bandadas de aves marinas, que se dirijían de la costa a la cordillera", (El Araucano, 1837). Y destaca además este científico en la misma publicación, que:

(...) el 20 de Enero, el volcan de Osorno. Al nordeste de Chiloé, estalló con increíble furia, i la lava se vió salir por la noche fuera del cráter, i descender cuesta abajo desde la cima del monte, que tiene 3,900 piés de elevación sobre el nivel del mar. La reverberacion de las llamas se extendía al duplo de la altura. (El Araucano, 1837)

Y así continúa con descripciones del fenómeno telúrico y sus réplicas hasta febrero en otros lugares de Chile, tales como la Bahía de Concepción, el puerto de Valparaíso, la Isla Sta. María, Talca, Chillán y otros lugares. Aquí, en esta noticia, el énfasis es destacar la magnificencia del fenómeno en sus aspectos geográficos, hidrográficos y vulcanológicos, más que en destacar la percepción social y cultural de los habitantes que lo vivieron.

\section{La mirada de la comunidad de científicos chilenos}

Por su parte, en cuanto a los estudiosos de las ciencias de la tierra, en Chile, ya a mediados del Siglo del Progreso, encontramos numerosos cultores como Domeyko, Pissis, Paulino del Barrio y otros, que analizan las características del cuerpo físico del país desde la perspectiva geográfica y geológica. Ante la imposibilidad de analizar los aportes de todos ellos, recordemos un trabajo del último de los mencionados, "Memoria sobre los temblores de tierra i sus efectos en jeneral i en especial los de Chile", de Paulino del Barrio, publicado en los Anales de la Universidad de Chile (1855). Y un trabajo de Ignacio Domeyko de mediados del siglo del Progreso.

Así, por ejemplo, en un trabajo de Paulino del Barrio, se observa que el autor utiliza un modus operandis que se caracteriza porque parte dando cuenta de todo el estado de la cuestión acerca de los fenómenos geológicos conocidos como "temblores de tierra", explicando las propiedades de sus oscilaciones, los ruidos que lo acompañan y haciendo una completa clasificación de estos; además, el autor precisa los lugares geográficos en que tales fenómenos geológicos son más frecuentes, tanto en Europa, como en el Nuevo Mundo y las teorías que explican dichos fenómenos. Así, por ejemplo, en relación con los temblores ocurridos en la metrópolis, el autor expone las características de aquellos, en estos términos:

En Santiago de noventa $i$ dos temblores observados en tres años, veinte $i$ dos han sido precedidos i diez i nueve seguidos de cambios en el estado del cielo; números aun mui reducidos $i$ que juntos no alcanzan a dar siquiera la mitad del número de observaciones. Respecto de la 
relacion que puedan tener con el estado del cielo he aquí lo que resulta de esas mismas observaciones:

Con el cielo despejado. 51.

“ " celajado............................21.

“ " nublado.......................... 16.

" " lloviendo............................ 4.

“ “ neblina................................ 1.

I como poco mas o menos esos números representan el estado atmosférico de Santiago, se deduce que no hai relacion alguna entre la verificación de los temblores de tierra. (Barrio, 1855, p. 606)

Por lo anterior, no es extraño que dado el cúmulo de estudios sobre geología, geografía e hidrografía en el país, ya a mediados del Siglo del Progreso, en Chile, los científicos tengan muy claro la correlación existente entre el cuerpo físico del país y los fenómenos telúricos. En efecto, por ejemplo Ignacio Domeyko, percibe muy bien la cuaterna océano, valles, volcanes y terremotos y tiene muy claro que ha arribado a un país esencialmente telúrico y que el mismo sufre esporádicamente cambios geomórficos en sus costas, valles y cordillera. En relación con el terremoto de 1855, acaecido en Concepción, Domeyko destaca la salida de mar, la fuerza de la ola y su impacto en los barcos del litoral. En rigor, en un momento de su prosa, señala:

(...) como una media hora despues del gran sacudimiento que se sintió en el puerto de Talcahuano i echó a sus habitantes fuera de sus casas, la mar de la bahía se retiró tan lejos de la orilla que todos los buques anclados en ella, aun los que se hallaban en 7 brazadas de agua, quedaron en seco. Luego una inmensa ola abrió paso por la entrada occidental que separa la isla Quiriquina del continente, i corriendo con mucha rapidez por toda la parte de la bahía, barrió sus elevadas costas, arrebatando todo lo que hallaba en el camino $i$ alcanzando hasta la altura de 25 piés verticales sobre el nivel de las altas mareas del lugar. (Domeyko, 1857, p. 11)

Es interesante destacar, por otra parte, que el sabio polaco avecindado en Chile no se limita a la descripción de los movimientos telúricos y sus efectos en el cuerpo físico del país, sino que además sugiere algunas tareas que podrían sumir los chilenos para desarrollar y cooperar con los estudios geográficos y geológicos de Chile, entre estas, " (...)marcar en las rocas más firmes los niveles de las mareas antes y después de los terremotos" (Domeyko, 1857, p. 11). En esta mirada, por tanto, el énfasis es esencialmente geológico y pedagógico para estimular a los habitantes costeros a marcar los niveles de las mareas como una forma de contar con un catastro previo para realizar a continuación el registro analítico y especializado.

Por otra parte, en rigor, casi todos los estudiosos de las ciencias de la tierra en el Chile decimonónico, tienen muy claro el correlato entre el cuerpo físico del país, su dinamismo y vicisitudes y su potencial riqueza implícita. El geólogo Ramón Correa, señala en 1891, que necesariamente debemos aceptar que todavía la mayor parte del interior de la tierra está en estado de fusión, y que por ello no podríamos explicar de otra manera, el acrecentamiento del calor, la profundidad, las fuentes termales, los volcanes y la mayor parte de los movimientos del suelo en nuestro territorio (Correa, 1891, p. 42). Pero por otro lado, el mismo científico está muy consciente de que las características peculiares del cuerpo físico chileno son el resultado de solevantamientos de capas geológicas pretéritas, las cuales, a su vez, han posibilitado de manera futura la riqueza minera del país. Y lo expresa en estos términos:

En Chile, como se ve, el pórfido cuarzífero ha solevantado la formación calcárea, i en Caracoles los beneficios de las minas Descubridora, Deseada, Cautiva i Merceditas, etc, se deben a un chorro de pórfido cuarzífero. (Correa, 1891, p. 44).

Esta percepción de la naturaleza chilena asociada con la idea de una alta sismicidad que puede destruir las ciudades y afectar al dinamismo económico y social, en rigor ya desde los años sesenta del Siglo del Progreso, es aceptada como un factum en la comunidad científica chilena y ioh, sorpresa!, también en la comunidad científica internacional. En efecto en un texto de un historiador y geógrafo francés de los años sesenta del siglo XIX, al comenzar a describir el territorio chileno, destaca claramente esta situación, en estos términos:

(...) la República de Chile consiste en una faja larga y estrecha, contenida entre los Andes y el 
Pacífico, al Sud de la República de Bolivia, y al Norte de la Patagonia. Su capital es Santiago, cuya población asciende á 70.000 almas, hermosa ciudad y muy salubre, si bien expuesta á frecuentes terremotos. Valparaíso es un puerto muy comerciante, con 36.000 almas; La Concepción destruida en 1835 por un terremoto de tierra, recobra cada día su anterior esplendor.(Iriarte, 1861, p. 414)

Para nosotros como ciudadanos chilenos del Siglo $X X I$, es impresionante que ya en este período este autor francés tenga muy claro la dupla: República de Chile-terremotos, como elementos constitutivos de una dialéctica inevitable y propia del país.

De lo anterior, queda claro, por tanto, que los propios científicos, tanto del exterior como del país, observan el cuerpo físico de Chile asociado inevitablemente a los fenómenos telúricos; por ello algunos científicos articulan esta realidad con las teorías existentes en la época, abordando analíticamente las propiedades geológicas y mineralógicas de dicha naturaleza convulsionada. Otros, imbuidos de una mirada positivista que caracteriza a muchos de los sabios del período finisecular del siglo XIX y que entienden la praxis científica y el conocimiento científico como algo que necesariamente conducirá al bienestar material y al telos del progreso colectivo, tienden a ver este corpus físico, como un gigantesco reservorio para la explotación de las riquezas naturales, de los recursos hídricos y mineralógicos y agrícolas.

\section{El legado para las políticas públicas contemporáneas, la arquitectura y la educación}

A partir de las descripciones realizadas tanto por Darwin y por los trabajos de los diversos exponentes de la ciencia decimonónica en Chile, como también por la visión que nos ha legado la viajera María Graham, e incluso de algunos exponentes de la ciencia europea, queda muy claro que hay un correlato en las mismas; por ejemplo en cuanto a las facetas románticas observadas en los notorios trozos descriptivos de la naturaleza chilensis y en cuanto a la idea de la fuerza y del dinamismo aleatorio de la misma; así como también, se observa que casi todos estos autores manifiestan un énfasis positivista en tanto perciben el corpus físico de Chile, como un reservorio para la explotación de recursos tendientes a la obtención del progreso material y del bienestar espiritual de sus habitantes. María Graham por supuesto, no se puede incluir como positivista puesto que su mirada es esencialmente romántica, matizada de una fuerte policromía y centrada en la búsqueda de la armonía del paisaje como un todo y en la belleza de los especímenes florísticos en particular.

Y al mismo tiempo se observa que estos autores mencionados perciben que la naturaleza chilensis es un cúmulo de entidades corpóreas y de fenómenos vinculados a los procesos de la vida, los cuales hay que identificar, describir y clasificar, para vencer así las dificultades y vicisitudes del territorio, para poner dicho conocimiento al servicio de un programa científico y político que contribuya a la obtención de la riqueza. Esto, principalmente en autores más próximos al período finisecular decimonónico.

De lo anterior, se observa que autores como los aquí estudiados, han asociado claramente el cuerpo físico de Chile con una notoria sismicidad y con un manifiesto dinamismo telúrico, con la belleza del medio y con los procesos culturales de identidad nacional, así como con las tareas de construcción republicana de la época. Por tanto, desde nuestra contemporaneidad aquí en Chile y América, resulta pertinente preguntarnos cómo podemos aprovechar algunos aspectos de estas visiones que nos permitan internalizar mejor nuestro imaginario sobre la naturaleza chilena y generar así innovaciones en la educación latinoamericana. Después de todo ya es un factum la percepción de la comunidad científica sobre nuestra gea y la convicción de que debemos asumir plenamente esta realidad. Con razón en Chile, desde la arquitectura también se estima conveniente precavernos al respecto y tener presente la necesidad de rehacer o reestructurar los espacios arquitectónicos urbanos para cautelar una mejor convivencia como ciudadano y ser humano en general. 0 en palabras de un arquitecto:

En Chile, a la altura del 2011-2012 tenemos actualizado además los peligros de los maremotos o tsunamis, de las erupciones volcánicas, de inundaciones por aguas lluvias, de deslizamientos al pie de montes de materiales de cualquier tipo, incluyendo acumulación de nieves. Estas realidades no gobernables de la Naturaleza en la Ciudad deben llevarnos a amar y cuidar la "Naturaleza Urbana" como un componente básico de la Ciudad en sus aportes a nuestra calidad de vida y a sus peligros. (Larraguibel, 2014, p. 13) 
Y por supuesto, en el plano educacional también podemos preguntarnos al menos lo siguiente: ¿cómo podemos aprovechar dicho conocimiento histórico y sistemático de la comunidad de los científicos decimonónicos chilenos y extranjeros para la realidad educacional contemporánea? ¿de qué manera podemos aprovechar esa rigurosa y completa mirada de los viajeros y científicos que recorrieron Chile?; ello, pensando en apoyar la formación de nuestros jóvenes para que comprendan mejor los sucesos de la naturaleza chilensis, y por extensión de la naturaleza americana y su dinamismo.

Al respecto, y como propuesta para generar posteriores trabajos más especializados en el plano de la inserción curricular propiamente, se sugiere a las personas que confeccionan los currículos, orientadores, sociólogos educacionales, gestores de políticas educacionales u otros especialistas, trabajar en dos frentes de acción en los sistemas educacionales de enseñanza media.

1. Articular constructos curriculares para la difusión de la realidad sísmica chilena o americana.

2. Organizar "Talleres de desarrollo personal", centrados en la importancia de los valores éticos, en relación con la realidad sísmica americana.

Ahora bien, en cuanto a lo primero, esto es, articular constructos curriculares para la difusión de la realidad sísmica chilena desde sus antecedentes históricos debidamente consignados, hasta las expresiones telúricas más contemporáneas, pero no como listas de datos históricos, sino como algo interdisciplinario, que concite los esfuerzos creativos y organizacionales de diversos exponentes del saber. Por ejemplo, en los tres últimos niveles de la enseñanza media, realizar una semana de Jornadas de Estudios de la Gea Latinoamericana, orientados a una mirada holística de los fenómenos propios de las ciencias de la tierra, con exponentes internos e invitados externos y cuyo leiv motif sea la obtención de una mayor interacción dialógica y cognitiva entre expositores y alumnos(as). Ello de partida, en tanto se presente como algo muy especial, agendado con antelación y enfatizado sistemáticamente por los docentes, ojalá con cobertura de medios comunicacionales; debería llamar la atención de los estudiantes pues lo percibirían como un corte en la rutina de clases y como una ocasión para acercarse a destacados científicos nacionales que solo se visualizan en los diarios y la TV. Y por tanto, con una disposición anímica positiva, es altamente probable que se internalicen mejor en los jóvenes las características de la naturaleza física del país, y vayan asumiendo dichas peculiaridades como parte de un imaginario colectivo nacional. Esto es, mutatis mutandis, algo así como Las semanas de Ciencia y Tecnología, que algunos países de nuestro continente tienen en sus programas educacionales y que -en Chile por ejemplo- han empezado a desarrollar desde la década de los noventa(Díaz y Saldivia, 1995, p. 42-45).

También en este ámbito de desarrollar en nuestros jóvenes una clara conciencia de nuestra gea telúrica, resultaría oportuno informarles tanto a ellos como a sus padres y apoderados, que desde el arte también se percibe una inquietud por asimilar nuestra realidad. En efecto, en la música, por ejemplo, el compositor y director de orquesta chileno Sebastián Errázuriz está muy consciente de los vaivenes de nuestra naturaleza y por ello recientemente ha preparado una obra musical denominada " Geografía del desastre" que es el resultado de la inspiración del autor tras el terremoto del 27 de febrero del 2010. Resulta impactante al respecto, escuchar las palabras de este músico sobre esta composición: "La obra también tiene que ver con comentar un país de desastres. Y lo mismo se puede aplicar a las relaciones humanas. Nos sentimos tan bien, estamos en la cumbre del éxito, y de repente se fractura todo" (El Mercurio, 11-05-2014).

Lo anterior, ilustra claramente que los artistas chilenos tienen plenamente internalizados las vicisitudes de nuestra geografía y están dispuestos a difundir sus creaciones inspiradas en nuestros dolores y en nuestros sufrimientos ocasionados por los movimientos telúricos para que las aceptemos como parte de nuestra realidad chilensis y podamos enfrentar los nuevos avatares de la naturaleza.

Y en relación con los Talleres de desarrollo personal, centrados en la importancia de los valores éticos universales y basados en el estudio de casos de los eventos telúricos y de erupciones volcánicas, cabe señalar que estos pueden ser desarrollados paralelamente en el período agendado para los constructos curriculares asignados a la difusión de la realidad sísmica chilena o americana. Y podrían realizarse bajo el alero de asignaturas como filosofía, ética, psicología, comunicación, arte, u otras. El objetivo central de tales sesiones sería: generar 
espacios colectivos para liberar los sentimientos y emociones de los estudiantes en relación con los fenómenos telúricos, sea en virtud de vivencias personales o de familiares de mayor edad, que les hayan impactado, o de relatos existentes en la literatura y/o medios de comunicación locales o nacionales. Lo anterior, con el fin de identificar ciertas conductas o acciones, que en tales situaciones manifestamos los seres humanos y valorarlas así, en sus dimensiones positivas y negativas en cuanto a su generosidad, entrega, desinterés, amor, hermandad, cooperación, sacrificio, filantropía, ternura, respeto y asertividad, o no de las mismas. Todo lo cual, debidamente encausado, puede constituirse en instancias de introspección y en una adecuada ocasión para rescatar los valores universales y desear alcanzarlos como estudiante y como persona.

\section{REFERENCIAS BIBLIOGRÁFICAS}

Universidad de Chile. Anales de la Universidad de Chile, correspondientes al año de 1843 i al de 1844, (1846, Octubre). Santiago: Impr. El Siglo.

Barrio, P.(1855, octubre) Memoria sobre los temblores de tierra i sus efectos en jeneral i en especial los de Chile, Anales de la Universidad de Chile, Santiago. p.606.

Correa, R.(1891) Nociones Jenerales de Jeolojía profesadas en la Escuela Práctica de Minas de Santiago. Santiago: Impr. Nacional. p.42 y ss.

Claro Tocornal, R.(2007)A un siglo del terremoto de Valparaíso, 1906-2006, Bol. de la Academia
Chilena de la Historia.; Año LXXIII. №116, Santiago. p.9

Darwin, C.(1945)Viaje de un naturalista alrededor del mundo, Buenos Aires: Librería El Ateneo. p.349.

Diario El Araucano, (1837, 27 de enero) Santiago, Chile, $\mathrm{N}^{\circ} 334$.

Diario El Mercurio, (2014, 11 de mayo) Santiago, Chile.

Díaz, y Saldivia, Z.(1995) La difusión científica en la enseñanza media: un ejemplo en Chile, Revista Occidente, №354, Mayo, Junio, Julio.

Domeyko, I.: Sobre el Solevantamiento de la Costa de Chile, Revista de Ciencias i Letras, T.I, $\mathrm{N}^{\circ} 1$, Stgo., 1857. pp. 9 y ss.

Graham, M.(1909)Diario de su residencia en Chile durante el año de 1822 i de su viaje de Chile al Brasil en 1823, T.II, Santiago: Impr. Cervantes. p.205.

Iriarte, T. (1861)Lecciones Instructivas sobre la Historia y Geografía. París: Librería de Garnier Hnos.

Larraguibel, F. (2014) Conceptualización de los Términos Ciudad, Diseño, Urbanismo y Arquitectura desde la perspectiva Ecoambiental, Revista Trilogía, Vol. 25, №35.

Urzúa Valenzuela, G.(1970) Evolución de la Administración Pública Chilena (1818-1968), Santiago: Ed. Jurídica de Chile. p.88. 